\title{
Factors Predicting Stress among Nurses in the Situation of Unrest of the Four Southern Border Provinces of Thailand
}

\author{
Nidarat CHOOWICHIAN ${ }^{1}$, Darawan THAPINTA ${ }^{2, *}$, \\ Hunsa SETHABOUPPHA ${ }^{2}$ and Petsunee THUNGJAROENKUL ${ }^{2}$
}

\author{
${ }^{1}$ School of Nursing, Walailak University, Nakhon Si Thammarat 80160, Thailand \\ ${ }^{2}$ Faculty of Nursing, Chiang Mai University, Chiang Mai 50200, Thailand
}

('Corresponding author's e-mail: darawan1955@gmail.com)

Received: 16 July 2018, Revised: 2 March 2019, Accepted: 23 April 2019

\begin{abstract}
Stress is a significant health problem among nurses working in areas of political unrest and war. It can pose a negative impact on local health systems. This study aimed to explore the relationship of factors and their ability to predict stress. Factors included the severity of the situation of unrest, sense of coherence, commitment, self-efficacy, and social support that exists among nurses in these situations. The subjects were 300 nurses selected by multi-stage random sampling. Data were analyzed using Pearson's product-moment correlation, and stepwise multiple regression. The results indicated that the severity of the situation of unrest was positively significantly associated with stress among nurses at a high level $(\mathrm{r}=.527, \mathrm{p}<.01)$ and sense of coherence $(\mathrm{r}=-.272, \mathrm{p}<.01)$ was negatively significantly associated with stress among nurses at a low level.The severity of the situation of unrest, sense of coherence, and social support together predicted $32.2 \%$ of the variance in stress among nurses. The severity of the situation of unrest was the most significant predictor of stress $(27.7 \%)$, followed by sense of coherence $(3.4 \%)$ and social support $(2.1 \%)$. Two factors associated with stress were the severity of the situation of unrest and sense of coherence, and three factors that predicted stress among nurses were the severity of the situation of unrest, sense of coherence, and social support. The findings can be used as basic data for nursing administrators to plan actions to prevent and deal with stress among nurses in situations of unrest by focusing on such predicting factors.
\end{abstract}

Keywords: stress, nurses, severity of situations of unrest, sense of coherence, social support

\section{Introduction}

"Unrest" is dissatisfaction and disagreement among people in a community, which can lead to aggressiveness and violence. The particular negative effects include physical injuries, damage to property, and sometimes death [1]. It is the result of relationship problems that may exist for a single person, or even among groups of people. The cause of the event is a general or specific issue that involves the use of power. It can be a national, international, political, social, or discriminatory issue. Factors that affect the severity of the event depends on the frequency, duration, location, number of participants, any influence of radical groups, and the type of confrontation occurring between opponents. It is controlled by law enforcement through police action and can lead to societal and cultural changes [1,2]. The event can cause many deaths and disabilities, and can give rise to specific diseases and other negative conditions [35]. The results of these events lead to burdens on health care systems [6]. A study done on the current level of global unrest showed that unrest existed in 170 countries in the period from 1919 to 2008 that had lasted for a long time. It was estimated that the distribution of the number of events per year tended to be associated with insurgencies spreading into surrounding geographical territories well beyond their points of origin [2]. 
http://wjst.wu.ac.th

At present, the situation of unrest existing in four southern border provinces of Thailand is referred to by a variety of terms, such as conflict [7], civil unrest [2], social unrest [8], collective violence [9], and man-made disaster [10]. It is defined as a man-made disaster if it is caused by a group of people with their own objectives and agendas [10]. Since January 2004, four southern border provinces of Thailand have experienced unrest. These areas of unrest are the Narathiwat, Pattani, and Yala Provinces, and parts of Songkhla Province, all of which have also seen an increase in violence and numerous other types of negative incidents. The violence has taken a variety of forms, such as arson, shooting, ambush, killing and bombings. Less openly violent, but nonetheless disruptive, acts include threatening telephone calls, sprinkling nails on the road, and scattering leaflets. This series of events started a long time ago, and have continued until today, with 14,128 recorded events of unrest, which have caused 6,097 deaths and 10,908 injuries [11,12], involving physical injuries, mental health problems, and changes in the social life of civilians and workers. This is especially true for nurses living and working in Thailand [13-15].

Clearly, nurses working in areas of unrest are a group that are both directly and indirectly affected by situations of unrest. The direct effects are the same as civilians living with families in areas of intense unrest [13]. People face violence, injury, and death daily in these situations $[15,16]$. The indirect effects can be due to the management of the situations of unrest [17]. In addition, in areas of unrest, nurses have to care for a large number of critical trauma victims, deal with death and dying, and work under great pressure in unsafe environments [18]. Therefore, these situations can produce high levels of stress.

A few studies have investigated the prevalence of stress among nurses in the southern provinces that have experienced unrest. Sama-Air (2008) examined stress in 240 health care workers at health centers in Narathiwat Province and found that $57.9 \%$ had stress at a moderate level, $34.69 \%$ at a mild level, and $7.08 \%$ at a high level [19]. Similarly, a study by Boonyoung et al. [20] examined the prevalence of stress among 97 nurse administrators, head nurses, nursing directors, and supervisors working in community and provincial hospitals in Yala Province and Narathiwat Province. They reported that $72.2 \%$ of the participants showed stress at a moderate level, $25 \%$ at a low level, and $2.8 \%$ at a high level [20]. In addition, a few studies on other workers have been done. Pricha [21] explored stress in police officers in Narathiwat Province and found that $54.3 \%$ had stress at a moderate level, $32.7 \%$ at a mild level, and 13 $\%$ at a high level [21]. Pliankerd [22] reported that stress in 342 soldiers stationed in Narathiwat Province was relatively high $(\overline{\mathrm{x}}=50.178, \mathrm{SD}=8.078)$. One can conclude that a majority of workers, such as nurses who work in areas of unrest, have at least a moderate level of stress.

Stress can be assessed as a stimulus, as a response, and as a transaction [23]. Stress as a stimulus involves the events or environments influencing a person to feel pressured or aroused [24]. Stress as a response is viewed as a response to noxious stimuli or environmental stressors, as well as nonspecific responses of the body to noxious stimuli [25]. Stress as a transaction is a particular relationship between the person and the environment that is appraised by the person as taxing, or that exceeds what available resources can mediate, thus endangering one's well-being [23]. In this current study, the researchers studied stress among nurses in areas of unrest based on the transactional model of stress and coping [23]. The authors believed that the outcome of this study could help nurses cope with stress.

Stress can impact one's physical, psychological, social, and spiritual wellbeing, as well as health care services. Physical impacts include increased incidence of cardiovascular disease, diabetes, gastrointestinal problems, and immune dysfunction [26,27]. Psychological impacts on nurses can lead to a lack of compassion and empathy for those under their care, as well as burnout [28] and depression [29]. Nurses reported that the social impacts resulting from being in situations of unrest contributed to lower participation in both formal and informal social groups [30]. Spiritual impacts on one's morale include feelings of helplessness and hopelessness [31]. Finally, health care services that were negatively impacted by stress can result in lower quality of patient care, insufficient attention to patient safety, and greater turnover rate [32,33]. It can be seen that stress significantly affects nurses' health and the overall health care system. Nurses represent the biggest group of health care providers and are one of the hardest positions for staff.

According to a recent literature review, it can be seen that most nurses in areas of unrest experience stress from living and working in unsafe situations. Again, this type of stress affects both nurses' health and the overall health care system. Stress levels among nurses in these four southern border provinces of 
http://wjst.wu.ac.th

Thailand that are experiencing unrest is of particular interest, especially with regard to the effects on culture and society. In Thailand, there have been two quantitative studies $[34,35]$ which examined factors related to stress among nurses in more normal situations. There have also been two qualitative studies $[14,36]$ that studied the working experiences of professional nurses in areas of unrest in three southern border provinces of Thailand. These studies determined that nurses had fear and stress from working in these conditions. In addition, there have been two studies [22,37] done on other workers in areas of unrest, such as soldiers, to examine factors related to stress. These factors included senses of coherence and social support. As aforementioned, only a few studies have examined factors related to stress among nurses in normal situations and other workers in areas of unrest of the four southern border provinces. Consequently, there is a lack of evidence about factors related to stress and factors predicting stress among nurses in the situation of unrest in these four southern border provinces of Thailand.

This study aimed to investigate factors related to stress and factors predicting stress based on the transactional model of stress and coping theory among nurses working in areas of unrest. Situational factors included the severity of the situation of unrest. Additionally, personal factors included commitment, a sense of coherence, self-efficacy, and social support. The results will provide evidence necessary for identifying stress factors in order to reduce stress for the nurses working in these regions of the country. These findings may also be used to plan prevention for lowering the levels of stress and provide intervention to reduce the moderate to high levels of stress among nurses in the situation of unrest.

\section{Materials and methods}

This study was a cross-sectional predictive correlational design conducted to identify and explain the factors, which included a situational factor (severity of the situation of unrest) and personal factors (commitment, sense of coherence, self-efficacy, and social support) for relationships existing among them as a means to predict increasing stress levels among nurses working in these four southern border provinces of Thailand. Data were collected between April 2016 and November 2016. The settings of the study were emergency units, surgery units, or intensive care units in secondary and tertiary hospitals in four southern provinces of Thailand (the Narathiwat, Pattani, and Yala Provinces, and parts of Songkhla Province), all of which had been affected by the situation of unrest. The sample consisted of 300 nurses who were full-time staff and had worked in their positions for at least six months. A multi-stage random sampling method was used. This study was approved by the Research Ethics Committee, Institutional Review Board (IRB) of the Faculty of Nursing, Chiang Mai University (study code: EXP - 136 - 2558), as well as the Ethical Review Board of Yala Hospital (study code: 11/2559). In addition, Pattani Hospital, Narathiwat Hospital, and the Songkhla, Pattani, Yala, and Narathiwat Provincial Public Health Offices have accepted the ethics approval of the Institutional Review Board, the Faculty of Nursing, Chiang Mai University.

Data collection was conducted after ethics approval was obtained. A research package containing the research proposal, an information sheet, an informed consent form, and a copy of the data collection tool was sent to the directors of the 30 hospitals in the four southern border provinces of Thailand for approval, and permission was obtained to collect data. The nursing directors of the 30 hospitals were informed of the objectives of the study by the researcher. The list of names of the nurses of each hospital was obtained from the nursing department of these hospitals. The whole procedure of data collection was explained to the subjects by the researcher. One staff nurse for each hospital was requested to be a research coordinator, and they assisted with data collection. The subjects were selected using a simple random sampling method from the name list in each unit of the 30 hospitals. Nurses who were subjects for the reliability testing were excluded from the sampling. The package of questionnaires, consisting of an Informed Consent Form, a Demographic Data Recording Form, a Severity of the Unrest Situation Questionnaire, a Modified Stress Appraisal Questionnaire, a Stressful Appraisal Questionnaire [38], an Organizational and Professional Commitment Questionnaire [39], a Sense of Coherence Scale (SOC-29 items) [40], a Perceived Self-Efficacy Scale [41], and a Personal Resource Questionnaire (PRQ 85 part II) [42], as well as a return envelope, was distributed to the subjects, who had agreed to cooperate by 
completing the questionnaires in their spare time. The information sheet explained the objectives of study, method for assurance of confidentially and anonymity, and time frame for completion of the questionnaires. The research coordinators asked the participants to return the completed questionnaires within two weeks. The researchers received all questionnaires from the research coordinators and screened them for completeness before analyzing the data.

\section{Data analysis}

Descriptive statistics were computed for demographic characteristics. The data on the relationship between stress among nurses in the situation of unrest of the four southern border provinces of Thailand and severity of the situation of unrest, commitment, sense of coherence, self-efficacy, and social support were tested using Pearson's product moment correlation analysis. Factors predicting stress among nurses in the situation of unrest of the four southern border provinces of Thailand were tested using stepwise multiple regression analysis. All variables met assumption, and significance level alpha was set at 0.05. Other demographics that might be associated with stress as covariates, including gender, religion, and working experience, were controlled before statistical analysis.

\section{Results and discussion}

\section{Results}

The subjects included 300 nurses (response rate $=100 \%$ ) who were working in 30 hospitals in an area of unrest in the four southern border provinces of Thailand. The demographic characteristics of nurses are presented in Table 1.

Table 1 Demographic characteristics of nurses $(n=300)$

\begin{tabular}{lcc}
\hline Characteristics & Frequency & Percentage \\
\hline Gender: & 37 & 12.3 \\
$\quad$ Male & 263 & 87.7 \\
$\quad$ Female & & \\
Education & 294 & 98 \\
$\quad$ Bachelor's degree & 6 & 2 \\
$\quad$ Master's degree & & 47.7 \\
Age $\quad$ Range $=22-60, \overline{\mathrm{x}}=28.41, \mathrm{SD}=5.92)$ & 143 & 31.3 \\
21-30 & 94 & 21 \\
31-40 & 63 & 32 \\
$\quad$ More than 40 & & 64.3 \\
Marital Status & 96 & 3.7 \\
Single & 193 & \\
Married & 11 & 33.3 \\
$\quad$ Divorced/Widowed & & 66.7 \\
Religion & 100 & \\
Buddhism & 200 & \\
Islam & &
\end{tabular}


http://wjst.wu.ac.th

\begin{tabular}{lcc}
\hline Characteristics & Frequency & Percentage \\
\hline Family Income & 225 & 75 \\
$\quad$ Insufficient & 9 & 3 \\
Sufficient & 66 & 22 \\
Debt & & \\
Address (Hometown/ Residency) & 281 & 93.7 \\
$\quad$ In civil unrest areas (3 provinces and 4 districts of & & \\
$\quad$ Songkla Province ) & 19 & 6.3 \\
$\quad$ Not within areas of unrest & & 1 \\
Length of employment in civil unrest areas & 3 & 0.7 \\
6 months - 1 year & 2 & 60.3 \\
More than 1 year - 3 years & 181 & 38 \\
More than 3 years - 10 years & 114 & \\
More than 10 years & &
\end{tabular}

With regard to the demographic characteristics of nurses in situations of unrest as presented in Table 1, the vast majority of nurses were female $(87.7 \%)$, and the age of nurses ranged from 21 to 30 years $(47.7 \%)(\overline{\mathrm{x}}=28.41, \mathrm{SD}=5.92)$. The majority of nurses had obtained a bachelor's degree $(98 \%)$. Their marital statuses were married (64.3\%), single (32\%), and divorced/widowed (3.7 \%). Islam was the most dominant religion (66.7\%), and the majority of them had hometown/residency in these areas of unrest $(93.7 \%)$. In addition, the length of employment in situations of unrest ranged from more than 3 years to 10 years $(60.3 \%)$, followed by more than 10 years $(38 \%)$ and 6 months to 1 year $(1 \%)$.

The independent variables as predictors of stress for nurses in the situation of unrest are displayed in Table 3. The findings show that the mean score of sense of coherence was 146.0433 (SD = 18.93065), with scores ranging from 104 to 191 . The mean score of social support was 134.1200 $(\mathrm{SD}=12.59156)$, with scores ranging from 96 to 196 . The mean score of commitment was 3.8211 ( $\mathrm{SD}=.46215)$, with scores ranging from 2.80 to 5 (high level). The mean score for self-efficacy was 76.9867 ( $\mathrm{SD}=7.68179$ ), with scores ranging from 59 to 98 (fairly high level). The mean score of severity of the situation of unrest was 99.1067 ( $\mathrm{SD}=21.58429)$, with scores ranging from 29 to 167 (medium level). Lastly, the mean score of stress was $1.1408(\mathrm{SD}=.46804)$, with scores ranging from 0 to 2.38 (moderate level).

As shown in Table 2, there were statistically significant relationships between two independent factors and stress. The severity of the situation of unrest was positively related to stress $(r=.527, p<.01)$, whereas sense of coherence was negatively related to stress $(\mathrm{r}=-.272, \mathrm{p}<.01)$. Also, the findings showed that the other three variables of commitment $(r=-.089)$, self-efficacy $(r=-.079)$, and social support $(r=-$ .021) were not significantly related to stress. 
http://wjst.wu.ac.th

Table 2 Correlation of coefficients between stress among nurses in the situation of unrest and independent variables $(n=300)$

\begin{tabular}{lcccccc}
\hline Variables & $\mathbf{1}$ & $\mathbf{2}$ & $\mathbf{3}$ & $\mathbf{4}$ & $\mathbf{5}$ & $\mathbf{6}$ \\
\hline $\begin{array}{l}\text { 1. Stress } \\
\text { 2. The severity of }\end{array}$ & 1 & & & & & \\
$\quad$ the situation of unrest & $.527^{* *}$ & 1 & & & & \\
3. Sense of coherence & $-.272^{* *}$ & $-.220^{* *}$ & 1 & & & \\
4. Commitment & -.089 & $-.147 *$ & $.391^{* *}$ & 1 & & \\
5. Self-efficacy & -.079 & -.087 & $.539^{* *}$ & $.453^{* *}$ & 1 & \\
6. Social support & -.021 & $-.117 *$ & $.504^{* *}$ & $.408^{* *}$ & $.486^{* *}$ & 1 \\
\hline \multicolumn{1}{c}{$\mathbf{x}$} & 1.1408 & 99.1067 & 146.0433 & 3.8461 & 76.9867 & 134.1200 \\
\hline$\quad$ SD & .46804 & 21.58429 & 18.93065 & .44822 & 7.68179 & 12.59156 \\
\hline \multicolumn{1}{c}{ level } & moderate & medium & high & high & fairly good & high \\
\hline
\end{tabular}

$* \mathrm{p}<.05, * * \mathrm{p}<.01$.

Table 3 Multiple regression analysis of the predictors of stress among nurses in the situation of unrest (n $=300$ )

\begin{tabular}{lccccc}
\hline \multicolumn{1}{c}{ Variables } & B & SE & B & t value & P \\
\hline Constant & .170 & .287 & & .593 & .554 \\
The severity of the situation of & & & & & \\
unrest & .011 & .001 & .492 & 10.025 & $.000^{*}$ \\
Sense of coherence & -.006 & .001 & -.245 & -4.340 & $.000^{*}$ \\
Social support & -.006 & .002 & -.160 & -2.888 & $.004^{*}$ \\
Commitment & -.019 & & -.017 & -.321 & .748 \\
Self-efficacy & -.027 & & -.027 & -.457 & .648 \\
\end{tabular}

Note. $\mathrm{R}=568, \mathrm{R}^{2}=.322$, Adjusted $\mathrm{R}^{2}=.315, \mathrm{~F}(3,296)=46.910, * \mathrm{p}<.01$ 
http://wjst.wu.ac.th

As presented in Table 3, three factors could significantly predict stress. The beta value showed that the severity of the situation of unrest had the strongest predictive power $(\beta=.492, p<.01)$ followed by sense of coherence $(\beta=-.245, p<.01)$ and social support $(\beta=-.160, p<.01)$. These predictors could explain $32.2 \%$ of the variance in stress among the nurses in the situation of unrest. The findings also suggest that the other two variables, commitment and self-efficacy, were not significant in predicting stress.

Discussion

This cross-sectional predictive correlational study was conducted to answer the research questions regarding the association of independent variables, based on the transactional model by Lazarus and Folkman [23], where situational factors and personal factors are important in the cognitive appraisal process. There were five factors to consider - the severity of the situation of unrest, sense of coherence, commitment, self-efficacy, and social support. This study identified whether these factors were related and influenced stress among nurses in situations of unrest existing in these four southern border provinces of Thailand.

In order to determine relationships between factors of stress among nurses in the situation of unrest of the four southern border provinces of Thailand, the severity of the situation of unrest, commitment, sense of coherence, self-efficacy, and social support were examined. The findings showed a positive relationship existing between the severity of the situations of unrest and stress $(r=.527, p<.01)$ and a negative relationship between sense of coherence and stress $(r=-.272, p<.01)$. On the other hand, the other factors, including commitment, self-efficacy, and social support, were not considered significant, and had a negative and low relation to stress among nurses in the situation of unrest. The severity of the situation of unrest was defined and developed following the situational factor. Nurses who lived and worked in these areas of unrest appraised these situations in terms of novelty, predictability, and event uncertainty using three temporal factors of imminence, duration, and temporal uncertainty. The severity of the situations of unrest could affect stress appraisal among nurses. A possible explanation for the findings of this study is that most nurses appraised these events as experienced, unpredictable, and uncertain. Furthermore, the time period of these events was determined as imminent, short time, and uncertain time, as the situation of unrest has occurred since 2004, and more than half of the nurses had nursing experience of 4-10 years. Therefore, they did not perceive these events as novel. Yet, they perceived the duration to face these events as short. Next, the results showed the level of severity of the situation of unrest to be at a moderate level, and stress was at a moderate level as well. The findings of the present study were consistent with those of other studies done elsewhere in Thailand. There is limited research currently available concerning the relationship between the severity of a situation of unrest and stress among nurses experiencing situations of unrest. However, there have been a few studies that investigated other workers, such as police officers and soldiers, in these areas. Yongyuan and Prakojcheu [43] examined the level of work stress, work factors, and personal factors among police officers in Pattani, which is one of the southern border provinces. The work stress factors included work characteristics and work environments. It was found that police officers rated work characteristics and environments as adding to stress; the staff were attacked by terrorists $(\overline{\mathrm{X}}=3.457)$, followed by excessive workload with less staff $(\overline{\mathrm{X}}=3.118)$, and the staff prepared too much before going out to work $(\overline{\mathrm{x}}=$ 2.828). Pliankerd [22] studied relationship and predicting factors of stress among soldiers stationed in Sri Sakhon District, Narathiwat Province, and found that the automatic negative thoughts in working in situations of unrest had a significantly positive moderate relationship with stress among soldiers in this area of unrest $(\mathrm{r}=.442, \mathrm{p}<.001)$ [22]. In international contexts, a study by Iversen et al. [44] examined risk factors and post-traumatic stress among United Kingdom armed forces personnel. They found that exposure to potentially traumatizing events, appraisal of experiences as involving threat to one's own life, and a perception that work in theatre was above one's individual trade and experience were strongly associated with post-traumatic stress $(\mathrm{p}<.001)$. Veronese and Pepe [45] studied the correlation between exposure to trauma experience and psychological distress in Palestinian aid workers and showed that the relation between exposure to trauma experience, including avoidance $(\mathrm{r}=.225, \mathrm{p}<.01)$ and 
intrusion/hyper arousal $(\mathrm{r}=.415, \mathrm{p}<.001)$, and psychological distress was positive and statistically significant. In addition, there have been a few hospital studies (emergency, intensive care units, etc.) that examined how work characteristics and work environments could lead to stress among nurses. These units had similar characteristics to those hospitals located in areas of unrest, such as dying patients, and physical and psychological trauma representing stressful events that these nurses must regularly face. A study by Siangpror et al. [46] was conducted on nurses from specialized cancer hospitals in the central region of Thailand. They found that working conditions had a significant relationship with stress among nurses $(\overline{\mathrm{X}}=15.730, \mathrm{p}<.05)$. Thangthum et al. [47] studied factors predicting stress among male nurses in Thailand and found that nurses working in the emergency units had a significant relationship with stress $(\overline{\mathrm{X}}=2.246, \mathrm{p}<.05)$.

Another factor, sense of coherence, is referred to as a general belief about control and the personality dispositions associated with a reduction in stress [48]. Nurses who had a sense of coherence were better able to view life's stressful events and had more comprehension (comprehensibility) and better understanding. Events were viewed as more reasonable (meaningfulness) and manageable (manageability). It promoted physical and mental readiness, self-confidence, a realistic attitude, problemsolving skills, and a positive outlook. Moreover, these nurses could effectively choose better resources to cope with stressful events in their lives and would perceive these situations as low stress. A possible explanation for this study finding is that these nurses demonstrated physical and mental readiness, self-confidence, a realistic attitude, problem-solving skills, and a positive outlook. Furthermore, they were better able to view stressful situations in the areas of unrest by having more comprehension and understanding. They could provide more sound reasoning, considered their work more meaningful, and managed stressful situations better. Thus, their personal and working lives were thought of as meaningful, challenging, and rewarding. They also felt their efforts were useful in their professions and daily life. In addition, they were more flexible and chose more effective resources for coping with specific situations in areas of unrest. Additionally, they perceived sense of coherence as being at a high level. However, there were other factors influencing stress. Consistent with earlier studies, sense of coherence was found to be at a high level in the present study, probably due to age [49,50], nursing experience [50], and social support [50,51]. In this study, more than half of the nurses were $31-60$ years old $(52.3 \%)$. Sense of coherence reaches the highest levels at the age of 30 years [49]. More than half of the nurses who worked in the situation of unrest had from 4 - 10 years of experience $(60.3 \%)$, and the vast majority lived in the areas of unrest $(93.7 \%)$. Nurses with higher knowledge and experience had a higher sense of coherence, as did nurses who lived in the area of unrest who had family and community resources as social support. Nurses who received social support from their family and community were expected to have a higher sense of coherence level. It is possible that these factors influenced nurses' ability to appraise the sense of coherence level. The findings of this study were consistent with those of other Thai studies as well. Although there is limited research about the relationship between the sense of coherence and stress among nurses in a situation of unrest, there have been studies done in other workers in situations of unrest. Chaiyapan [37] studied the relationships between sense of coherence and work stress among militiamen in three southern border provinces of Thailand, and found that a sense of coherence had a significant negative relationship with work stress $(r=-.59, p<.001)$ [37]. Similarly, in international contexts, Veronese and Pepe [45] studied the correlation between sense of coherence and psychological distress in aid workers, and sense of coherence was negatively correlated with psychological distress $(r=-.470, \mathrm{p}<.001)$. In addition, there have been a few hospital studies in similar areas. Jonsson et al. [52] studied the relationship between sense of coherence and post-traumatic stress among ambulance personnel in Sweden and reported a significantly negative relationship $(\mathrm{r}=-.403, \mathrm{p}<$ $.01)$. These studies showed post-traumatic stress that was similar to stress in the areas of unrest. A study by Yam and Shiu [53], who studied the relationships between sense of coherence and perceived stress among critical care nurses in Hong Kong, revealed that sense of coherence had a significantly negative relationship with perceived stress $(\mathrm{r}=-.64, \mathrm{p}<.001)$.

In contrast, although self-efficacy, commitment, and social support are personal factors in the transactional model of stress and coping, they had no relation with stress among nurses in situations of 
http://wjst.wu.ac.th

unrest in this study. Self-efficacy is an individual's beliefs about one's ability to control disturbing thoughts [54]. One possible explanation for this finding is that the nurses tended to have an ability to control their cognitive appraisal for their work and personal lives in these situations of unrest. The primary appraisal of the situation may have a great impact on influencing their perceptions of stress and their levels of stress. Self-efficacy is a personal factor influencing the secondary appraisal that could not contribute to the nurses' ability to control the stressful events in the areas of unrest. Therefore, this factor had no relationship with stress among nurses working in these areas. The findings of this study were congruent with a previous study which reported no relationship between self-efficacy and stress. Elkazaz and Berma [55] conducted a study on self-efficacy and stress among nurses in a neonatal intensive care unit and found that self-efficacy had no relationship with psychological stress. Their stressful environment was similar to the areas of unrest of this research, and so were the findings. On the contrary, two studies revealed that self-efficacy was related to stress, which was supported by the conceptual framework. Krithathip and Boonchaythanasit [56] studied the relationship between self-efficacy and coping with stress among nurses working at Pramongkutklao Hospital. The results revealed a significantly positive relationship between self-efficacy and coping with stress $(\mathrm{r}=.439, \mathrm{p}<.001)$. This represented a negative relationship with stress. Similarly, Welsh [57] found that fundamental and complex nursing care self-efficacy had a significantly negative relationship with stress among medical surgical nurses $(\mathrm{r}=.-19, \mathrm{r}=-.22$ respectively, $\mathrm{p}<.001)$.

Commitment is acceptance of the organization's goals and values, willingness to exert considerable effort, and a strong desire to maintain membership [58]. A possible explanation for no relationship between commitment and stress in this study is that nurses working in the situations of unrest demonstrated an acceptance of goals and values in their professions. They had a work ethic and a desire to maintain professional memberships, and their commitment level was high. The findings of this study were not in accordance with the high-commitment, low-stress theory. It is possible that the situational factor (the severity of situation) greatly affected primary appraisal. Commitment was a personal factor that affected secondary appraisal. The severity of situations of unrest had a larger impact on stress appraisal than the nurses' ability to control, which is commitment in these situations of unrest. Moreover, nurses in situations of unrest suffered high levels of stress, both in their personal and work environments. Commitment did not buffer the negative effects from many stressors in the areas of unrest. The findings of the present study were consistent with a previous study that found no relationship between commitment and stress. Lu et al. [59] studied the relationships between professional commitment, job satisfaction, and work stress among public health nurses in Taiwan and revealed that professional commitment did not have a relationship with work stress. In contrast, two studies reported findings that contradicted the present study.In Thailand, Tippakum [60] studied staff nurses in community hospitals and found that commitment had a significantly negative relationship with stress $(\mathrm{r}=-.162, \mathrm{p}<.01)$. Tippakum suggested that there might be other factors influencing stress. In other countries, Ghareeb et al. [61] analyzed the relationship between organizational commitment and work stress among emergency, intensive care, and surgical nurses in Egypt's Zagazig University Hospital. A negative relationship, with a statistical significance of $r=-.46, p<.001$, was found.

Social support is when a person is satisfied with the rising demands between the individual relationship and society-attachment, social integration, opportunity of nurturance, reassurance of worth, reliable alliance, and obtaining of guidance [62]. One possible explanation for no relationship between social support and stress in the present study is that, although nurses felt confident that they perceived social support from family members, co-workers, supervisors and community resources, as well as that they could adapt, manage, and make decisions in general crisis situations, in the areas of unrest in the four southern border provinces of Thailand, they felt that they could not adapt, manage or make decisions appropriately during crises. They utilized the primary process in stressful situations in the areas of unrest, leading to higher stress levels. Since primary appraisal was far more influential than secondary appraisal among nurses in the areas of unrest, social support, which was a personal factor in the secondary appraisal, did not reflect any relationship with stress among these nurses. The findings of this study could be supported by a previous study which demonstrated no relationship between social support and stress. Liangkobkit [63] studied relationships between personal factors, social support, and job stress among 
private hospital nurses in Bangkok, and found that social support had no relationship with job stress. However, the findings of the present study disagreed with three other studies. Siangpror et al. [46] studied nurses in cancer hospitals in the central region of Thailand and found that social support had a significant relationship with stress among nurses $\left(\mathrm{X}^{2}=14.571, \mathrm{p}<.01\right)$. Nurses with perceived low social support had a stress level of $4.51(95 \% \mathrm{Cl}$ : 1.91 - 10.64), which was much higher than nurses with high social support. Similarly, Yu et al. [64] and AbuAlRub [65] found that social support had a significantly negative relationship with stress among hospital nurses $(\mathrm{r}=-.253, \mathrm{p}<.05 ; \mathrm{r}=-.10, \mathrm{p}<.01$, respectively).

After analyzing the factors predicting stress among nurses in situations of unrest of these four southern border provinces of Thailand, it was found that the severity of the situations of unrest $(\beta=.492$, $p<.01)$, sense of coherence $(\beta=-.245, p<.01)$, and social support $(\beta=-.160, p<.01)$ together accounted for $32.2 \%$ of the variance in stress. The severity of the situations of unrest contributed most strongly to predictability. This variable explained $27.7 \%$ of the variance in stress. Sense of coherence was the second degree of contribution. This variable explained $3.4 \%$ of the variance in stress and, when computed with the severity of the situation of unrest, could explain $30.3 \%$ of the variance in stress. Next, social support was the third contributing variable of the equation. It explained $2.1 \%$ of the variance in stress and, when computed with the severity of the situations of unrest and sense of coherence, could explain $32.2 \%$ of the variance in stress.

This study found that the severity of the situation of unrest contributed most strongly to the predictive equation. One possible explanation is that nurses appraised living and their working lives as events that were not novel, unpredictable, or uncertain. Also, the time period of events was considered to be imminent, short, and uncertain. These situations were different from the stressful situations typically encountered in more typical environs. Nurses' perception of the high level of the severity of the situations of unrest affected their cognitive appraisal; therefore, they perceived stress as harm / loss. Nurses' perception of the low level of the severity of situations of unrest affected cognitive appraisal, and thus they perceived stress as a challenge. They appraised a situational factor in the primary process as having a larger impact on them than other personal factors weighed in the secondary process of analysis. The findings showed that the severity of the situation of unrest was the first predictor that contributed to stress. However, these situations have occurred for a long time, so any nurses who had experienced them also considered that the time of encountering such situations was short. Thus, the findings showed that the perceptions of the severity of the situations of unrest were predictors of low significance of stress. Sense of coherence was the second degree of contribution. Personal factors were one type of factor affecting cognitive appraisal [23]. One possible explanation for this finding is that nurses had physical and mental readiness, self-confidence, realistic attitudes, problem-solving skills, and positive outlooks. They were better able to view the stressful situations in the areas of unrest systematically and with understanding. They could provide sound reasoning with regard to tasks, felt that their work was meaningful, and could effectively manage the stressful situations. Nurses' perception of the high level of sense of coherence influenced cognitive appraisal. Therefore, they appraised stress as a challenge, while nurses who had a low level of sense of coherence appraised stress as harm/loss. However, in the primary appraisal, they considered the stressful situations in the situation of unrest as having a larger effect on them than a sense of coherence. Coherence, as one's ability to view stressful situations, is determined in the secondary appraisal. The findings showed sense of coherence to be the second predictor to contribute to stress and a predictor of low significance of stress. This was another factor influencing cognitive appraisal to appraise stress. Social support was the third contributing variable in the equation. Social support was another personal factor that affected cognitive appraisal [23]. The findings showed that social support had no relationship with stress, but it could be a predictor. Moreover, it was revealed that social support had a moderate relationship with sense of coherence $(\mathrm{r}=.504, \mathrm{p}<.01)$. One possible explanation for this finding is that social support had a role in reducing stress, so it was directly and indirectly related to stress prediction. Nurses acquired perceived social support from family members, co-workers, supervisors, and community resources. Furthermore, they adapted, managed, resolved, and made decisions appropriately in situations of unrest. Social support influenced cognitive appraisal and appraised stress. Although the results showed that perceived social support had a moderate relationship with sense of coherence, no direct relation to stress was particularly evident. Hence, social support might have an indirect effect on 
http://wjst.wu.ac.th

stress and influenced stress through sense of coherence. Nurses who had a high sense of coherence had the ability to select the most useful resources to deal with stressful situations. Social support was often selected as the factor that influenced cognitive appraisal and was related to appraising stress as a challenge. Moreover, social support had a direct relation to predicting stress. Nurses' perception of high social support influenced cognitive appraisal, and they therefore appraised stress as a challenge in the same way. This was the last factor influencing cognitive appraisal regarding stress.

Regarding the severity of the situation of unrest, the findings of the present study were in agreement with a previous study conducted in Thailand to investigate other workers in these areas. Pliankerd [22] studied factors predicting stress among soldiers stationed in Sri Sakhon District, Narathiwat Province, and found that the automatic negative thoughts in working in situations of unrest and social support from superiors could predict $22.1 \%$ of the variance in stress, with a statistical significance of .001 . Similarly, in international contexts, Veronese et al. [54] explored the influence of exposure to war experience and sense of coherence on psychological distress in Palestinian helpers in war contexts, and found that exposure to war experience and sense of coherence were significant predictors, accounting for $38.9 \%$ of the variance in psychological distress. In addition, there are a few hospital studies in similar areas. A study by Siangpror et al. [46] was conducted on nurses from specialized cancer hospitals in the central region of Thailand. They found that working conditions had a significant relationship with stress among nurses $(\overline{\mathrm{X}}=15.730, \mathrm{p}<.05)$. Nurses who had threatening working conditions indicated levels of stress of 3.31 (95\% Cl: $1.45-7.55)$, which were much higher than nurses who had typical challenging working conditions. Moreover, through analyzing predictors of specific cancer training, working conditions and social support together accounted for $28 \%$ of variance in stress. Thangthum et al. [47] studied factors predicting stress among male nurses in Thailand and found that nurses working in emergency units had a significant relationship with stress $(\overline{\mathrm{X}}=2.246, \mathrm{p}<.05)$. Nurses who worked in an emergency unit indicated a stress level of $1.94(95 \% \mathrm{Cl}: 1.45-3.35)$, which was much higher than those who worked in general units. Studies done in other countries included the study by Azida [66] to examine factors influencing perceived stress among nurses, which reported that $19.7 \%$ of the perceived stress could be explained by working conditions. Akinwolere [67] conducted a study on psychological stress in critical care nurses in the United States and demonstrated that working conditions accounted for $31 \%$ of variance in stress.

With regard to sense of coherence, these findings were in agreement with previous studies. In Thailand, Chaiyapan [37] studied the sense of coherence and work stress among militiamen in three southern border provinces, and found sense of coherence $(\beta=-.35, p<.001)$ to be a statistically significant predictor that had a direct impact on work stress among militiamen working in these areas of unrest. Similarly, in other countries, Veronese et al. [54] explored the influence of exposure to war experience and sense of coherence on psychological distress in Palestinian helpers in war contexts, and found that exposure to war experience and sense of coherence were significant predictors, accounting for $38.9 \%$ of the variance of psychological distress.

As regards social support, the findings of the present study were consistent with several previous studies. In a study conducted among other workers in these areas, Pliankerd [22] investigated factors predicting stress among soldiers stationed in Sri Sakhon District, Narathiwat Province, and showed that the automatic negative thoughts in working in situations of unrest and social support from superiors could predict $22.1 \%$ of the variance in stress, with a statistical significance of .001 . In addition, there were a few hospital studies in similar areas. A study by Siangpror et al. [46] was conducted on nurses from specialized cancer hospitals in the central region of Thailand. They found that the predictors of specific cancer training, working conditions, and social support together accounted for $28 \%$ of variance in stress, and nurses who had low social support indicated a stress level of 4.51 (95\% Cl: $1.91-10.64)$, which was much higher than those who received high levels of social support. Thangthum et al. [47] investigated factors predicting job strain among male nurses in Thailand and found that nurses who lacked social support from supervisors indicated a stress level of $2.48(95 \% \mathrm{Cl}: 1.40-4.39)$, which was much higher than those who received social support from supervisors. Ogińska-Bulik [68] determined the predictive role of social support for both negative and positive outcomes of experienced traumatic events in a group 
of male emergency service workers in Poland. The results indicated perceived support from supervisors to be a predictor of post-traumatic stress symptoms $(\beta=-.19, p<.05)$ and together accounted for $4 \%$ of the variance in post-traumatic stress. Perceived support from co-workers was a predictor of post-traumatic growth $(\beta=.31, \mathrm{p}<.01)$ and could explain $10 \%$ of the variance in post-traumatic growth.

Self-efficacy and commitment, in contrast, had no predicting ability on stress among nurses in the situation of unrest in the present study. Self-efficacy could explain stress in general situations, as nurses seemed to have self-efficacy to cope with stress in normal environments, but not in the situations of unrest. Similarly, high levels of commitment may be explained by the nurses' strong dedication to their profession and to their co-workers, rather than by stress from working in areas of unrest. This shows that these factors could not predict stress among these nurses. The findings of the present study contradicted one study in which self-efficacy and commitment could predict stress. Hamid [69] examined the predictability between socio-demographic variables, job stressors, and hardy personality among nurses in Iran, and revealed that hardy personality (commitment and control) was a significant predictor, accounting for $10 \%$ of the variance of emotional exhaustion, which was equivalent to stress.

In conclusion, there were only three factors related to the prediction of stress among nurses: the severity of the situations of unrest, sense of coherence, and social support. These independent variables together accounted for only $32.2 \%$ of the variance in stress, which was a dependent variable. These findings provided further evidence that the aforementioned factors played a role in stress among nurses in the situations of unrest. There is still a need to identify other factors that can predict stress in these nurses.

\section{Conclusions}

This study provided useful information for a better understanding of the relationships between the severity of the situation of unrest, sense of coherence, commitment, self-efficacy, and social support toward stress among nurses working in situations of unrest in the four southernmost provinces of Thailand, and was conducted to examine the ability of the severity of the situation of unrest, sense of coherence, commitment, self-efficacy, and social support to predict stress among nurses working in situations of unrest. Data were analyzed using descriptive statistics, Pearson's correlation, and stepwise multiple regression. First, correlation results showed that there was a significant positive relationship between the severity of the situation of unrest and stress among nurses in situations of unrest. There was also a significant negative relationship between sense of coherence and stress among nurses in situations of unrest. Lastly, the results of stepwise multiple regression revealed that the severity of the situation of unrest, sense of coherence, and social support were three independent variables which together accounted for $32.2 \%$ of the variance in stress among nurses in situations of unrest. These findings may also be used to monitor stress among nurses in the situation of unrest. This mental health problem should be regularly assessed, monitored, and evaluated to plan for prevention and intervention to reduce stress among nurses in the situation of unrest.

\section{Limitations}

This study has some limitations in that the majority of samples were female $(87.7 \%)$, and sex may have contributed to differences in stress appraisal and any factors involved. In addition, this study used a general assessment tool of perceived self-efficacy, which might not be specific to stress and the assessment of organizational and professional commitment. This might not represent the same level of commitment of the persons who have experienced these particular situations.

\section{Acknowledgements}

The author gratefully acknowledges her advisor and co-advisors for their valuable guidance and thoughtful recommendations in the development of this study. The author wishes to thank the personnel of the Provincial Public Health Offices and the 30 hospitals for their cooperation during the data 
http://wjst.wu.ac.th

collection process, as well as all the nurses in the four southern border provinces of Thailand who participated in the study. This research was funded by Walailak University, Thailand.

\section{References}

[1] B Ballantyne. Medical management of the traumatic consequences of civil unrest incidents. Toxicol. Rev. 2006; 25, 155-97.

[2] D Braha. Global civil unrest: Contagion, self-organization, and prediction. PloS One 2012; 7 , e48596.

[3] CM Evoy and G Hideg. Global Violent Death 2017: Time to Decide. Small Arms Survey, Graduate Institute of International and Development Studies, Geneva, 2017.

[4] World Health Organization. Global Status Report on Violence Prevention 2014. World Health Organization, Geneva, 2014.

[5] World Health Organization. Fact Sheet: Violence Prevention in the South-East Asia Region. World Health Organization, 2015

[6] R Lavin, TG Veenema, WJ Calvert, SR Grigsby and J Cobbina. Nurse leaders' response to civil unrest in the urban core. Nurs. Adm. Q. 2017; 41, 164.

[7] Crisis Group Asia Report. Thailand: The Evolving Conflict in the South. Crisis Group Asia Report, 2012.

[8] W Sae-Sia, P Songwathana, S Hirunchuha and H Sangchan. Continuum of care management for victims and families assaulted in the social unrest, Southern Thailand: A situation analysis (in Thai). J. Nurs. Sci. 2014; 32, 7-14.

[9] EG Krug, JA Mercy, LL Dahlberg and AB Zwi. The World Report on Violence and Health. Geneva, WorldHealth Organization, 2002.

[10] U Taemeeyapradit and K Makwichit. Posttraumatic Stress Disorder. Guideline for Psychological Impact of the Unrest in the South for Doctors and Pharmacists (in Thai). Mental Health Crisis Center, Songkhla Rajanagarindra Psychiatric Hospital, Songkla, 2005, p. 45-8.

[11] S Jitpiromsri. The new challenge of Thailand's security forces in southern frontiers. In: Proceedings of the International Conference on Political Science, Public Administration and Peace Studies, in Prince of Songkhla University, Hat Yai, Thailand, 2012.

[12] S Jitpiromsri. An inconvenient truth about the Deep South Violent Conflict: A decade of chaotic, constrained realities and uncertain resolution. Deep South Watch. Available at: http://www.deepsouthwatch.org/node/5904, accessed July 2015.

[13] S Kraonual. Nurses Practice Experiences in the Unrest Situation in the Three Southern Border Provinces of Thailand (in Thai). Ramathibodi Nurs. J. 2009; 15, 284-98.

[14] S Kraonual, U Hatthakit and U Boonyasopun. Meanings, feeling, motivation and conditioning factors of nurses' practice on the unrest situations of the three southern border provinces (in Thai). Thai J. Nurs. Council 2010; 24, 64-77.

[15] S Rittiruksa. Medical and public health management in unrest situation in Yala Province (in Thai). 12th Region Med. J. 2005; 16, 79-91.

[16] JL Herman. Complex PTSD: A syndrome in survivors of prolonged and repeated trauma. J. Trauma. Stress 1992; 5, 377-91.

[17] A Khunpech, S Hirunchunha and K Naka. Competency responding to public hazardous events perceived by community hospital nurses in three southern border provinces (in Thai). Thai Emerg. Med. J. 2009; 2, 24-36.

[18] B Alhajjar. 2013, Occupational Stress among Hospital Nurses in Gaza-Palestine. Ph.D. Dissertation. The University of Manchester, United Kingdom.

[19] M Sama-Air. 2008, Stress and Coping with Stress of Health Workers at Health Centers in Narathiwat Province. M.P.H.Thesis. Chiang Mai University, Chiang Mai, Thailand.

[20] N Boonyoung, P Siripunboon and S Phumdoung. Impact from unrest situations in the southernmost provinces on stress and coping, quality of life and nursing administration as perceived (in Thai). $J$. Med. Health Sci. 2009; 15, 175-87. 
http://wjst.wu.ac.th

[21] M Pricha. 2009, Factors Related to Stress and Stress Management Behaviors of Border Patrol Police Company 446 in Narathiwat Province, M.S.C. Thesis. Chulalongkorn University, Bangkok, Thailand.

[22] P Pliankerd. 2009, Factors Predicting Stress among Soldiers Stationed in Si Sakhon District, Narathiwat Province, M.S.C. Thesis. Chiang Mai University, Thailand.

[23] RS Lazarus and S Folkman. Stress, Appraisal, and Coping. Springer, New York, 1984.

[24] TH Holmes and RH Rahe. The Social Readjustment Rating Scale. J. Psychosom. Res. 1967; 11, 213-8.

[25] H Selye. Stress in Health and Disease. Butterworths, Boston, 1976.

[26] K Hirokawa, T Ohira, M Nagayoshi, M Kajiura, H Imano, A Kitamura, M Kiyama, T Okada and H Iso. Occupational status and job stress in relation to cardiovascular stress reactivity in Japanese workers. Prev. Med. Rep. 2016; 1, 61-7.

[27] D Milutinović, B Golubović, N Brkić and B Prokeš. Professional stress and health among critical care nurses in Serbia. Arh. Hig. Rada Toksikol. 2012; 63, 171-80.

[28] N Khamisa, B Oldenburg, K Peltzer and D Ilic. Work related stress, burnout, job satisfaction and general health of nurses. Int. J. Environ. Res. Public Health 2015; 12, 652-66.

[29] S Khalid, U Irfan, S Sheikh and M Faisal. Frequency of stress and depression in female nurses working in a teaching hospital. Kust. Med. J. 2010; 2, 10-4.

[30] N Goalder and L Schultz. Mental health nurse, burnout and stress: options for prevention. HNE Handover: For Nurses and Midwives 2008; 1, 36-8.

[31] S Kanjanakundee and D Patan. Peace in Flames. Nations Books, Bangkok, 2006.

[32] RF AbuAlRub and IM Al-Zaru. Job stress, recognition, job performance and intention to stay at work among Jordanian hospital nurses. J. Nurs. Manag. 2008, 16, 227-36.

[33] YM Park and SY Kim. Impacts of job stress and cognitive failure on patient safety incidents among hospital nurses. Saf. Health Work 2013; 4, 210-5.

[34] W Kunaviktikul, R Nuntasupawat, W Srisuphan and RZ Booth. Relationships among conflict, conflict management, job satisfaction, intent to stay, and turnover of professional nurses in Thailand. Nurs. Health Sci. 2000; 2, 9-16.

[35] PD Tyson and R Pongruengphant. Five-year follow-up study of stress among nurses in public and private hospitals in Thailand. Int. J. Nurs. Stud. 2004; 41, 247-54.

[36] S Mitreekun. 2007, Working Experience of Professional Nurse under Violent Situation in the Southern Border Provinces, M.N.S. Thesis. Chulalongkorn University, Bangkok, Thailand.

[37] M Chaiyapan. 2011, Relationship between Sense of Coherence and Work Stress of Militiamen in the Three Southern Border Province with Coping Styles as Mediating Variables, M.Sc Thesis. Chulalongkorn University, Bangkok, Thailand.

[38] B Changlek. 2005, Stress Appraisal and Coping of Health Personnel from the Situation of Unrest in the Southern Thailand, M.N.S. Thesis. Prince of Songkla University, Songkla, Thailand.

[39] S Boonraksa. 1996, Job Satisfaction and Organizational Commitment of Professional Nurses in Department of Mental Health, M.N.S. Thesis. Chiang Mai University, Thailand.

[40] S Hanucharurnkul. Conflict in daily life, sense of coherence, and well-being in academic nurses in university (in Thai). J. Nurs. Sci. 1989; 58, 169-90.

[41] J Sookdee. 2000, Perceived Self-efficacy and Health-Promoting Lifestyles among Incarcerated Women, M.N.S. Thesis. Chiang Mai University, Chiang Mai, Thailand.

[42] C Wannapornsiri. 1992, Relationship between Social Network, Social Support, and Mental Health of Nurses in Buddhachinnaraj Hospital, Phitsanulok Province, M.N.S. Thesis. Chiang Mai University, Chiang Mai, Thailand.

[43] B Yongyuan and S Prakojcheu. Work stress and personal factors affecting intention to move out of the three southern border provinces of the Pattani provincial police officers (in Thai). Songklanakarin J. Soc. Sci. Humanit. 2005; 11, 115-34.

[44] AC Iversen, NT Fear, A Ehlers, JH Hughes, L Hull, M Earnshaw, N Greenberg, R Rona, S Wessely and M Hotopf. Risk factors for post-traumatic stress disorder among UK Armed Forces personnel. Psychol. Med. 2008; 38, 511-22. 
http://wjst.wu.ac.th

[45] G Veronese and A Pepe. Sense of coherence as a determinant of psychological well-being across professional groups of aid workers exposed to war trauma. J. Interpers. Violence 2017; 32, 1899-920.

[46] P Siangpror, T Rawiworrakul and O Kaewboonchoo. Factors correlated to job stress among nurses in specialised cancer hospitals, central region of Thailand (in Thai). J. Health Sci. Res. 2014; 10, 17 27.

[47] W Thangthum, S Kalampakorn and S Lagampan. Factors predicting job strain among male nurses in Thailand (in Thai). J. Nurs. Divis. 2014; 4, 6-22.

[48] A Antonovsky. Unraveling the Mystery of Health: How People Manage Stress and Stay Well. Jossey-Bass; 1987.

[49] S Carmel and J Bernstein. Trait-anxiety and sense of coherence: A longitudinal study. Psychol. Rep. $1989 ; \mathbf{6 5}, 221-2$.

[50] K Suthaviresan. 1992, The Relationships Between Sense of Coherence, Social Support and Burnout among Critical Care Nurses, M.N.S. Thesis. Madhidol University, Bangkok, Thailand.

[51] MA Griffin and S Clarke. Stress and Well-Being at Work. In: S Zedeck (Ed.). Handbook of Industrial Organizational Psychology. APA Books, Washington DC, 2000, p. 359-95.

[52] A Jonsson, K Segesten and B Mattsson. Post-traumatic stress among Swedish ambulance personnel. Emerg. Med. J. 2003; 20, 79-84.

[53] B Yam and AT Shiu. Perceived stress and sense of coherence among critical care nurses in Hong Kong: A pilot study. J. Clin. Nurs. 2003; 12, 144-6.

[54] A Bandura. Perceived self-efficacy in cognitive development and functioning. Educ. Psychol. 1993; 28, 117-48.

[55] RH Elkazaz and AE Berma. Stress and Self efficacy Among Nurses in Neonatal Intensive care Units. Int. J. Res. Granthaalayah 2017; 5, 237-51.

[56] B Krithathip and K Boonchaythanasit. Relationship between self-efficacy and social support on coping with stress and coping with stress behaviors of nurses working in Pramongkutklao Hospital (in Thai). J. Health Sci. Res. 2016; 10, 1-7.

[57] DM Welsh. Occupational Stress, Self-Efficacy and Symptom Relationships among Medical-surgical Hospital Nurses. University of Kentucky, 2006.

[58] RT Mowday, RM Steers and LW Porter. The measurement of organizational commitment. J. Vocat. Behav. 1979; 14, 224-47.

[59] KY Lu, LC Chang and HL Wu. Relationships between professional commitment, job satisfaction, and work stress in public health nurses in Taiwan. J. Prof. Nurs. 2007; 23, 110-6.

[60] P Tippakum. 2000, Occupational Stress and Organizational Commitment of Staff Nurses in Community Hospitals Region 10, M.N.S. Thesis. Chiang Mai University, Chiang Mai, Thailand.

[61] NS Ghareeb, MM Aboserea and EE Oraby. Assessment of work stress and organizational commitment among female nurses at Zagazig University Hospitals, Sharkia Governorate, Egypt. Middle East J. Appl. Sci. 2014; 4, 86-95.

[62] R Weiss. The Provisions of Social Relationships. In: Z Rubin (Ed.). Doing Unto Others. PrenticeHaU, Englewood Cliffs, 1974, p. 17-26.

[63] J Liangkobkit. 2010, Relationships between Personal Factors, Work Endeavor, Social Support, and Job Stress in Professional Nurses, Private Hospitals, Bangkok Metropolis. Master's Thesis, Chulalongkorn University, Bangkok, Thailand.

[64] J Yu, X Ren, Q Wang, L He, J Wang, Y Jin, Y Chen, L Wang, Z Nie, D Guo and Y Yao. The role of social support on occupational stress among hospital nurses. Int. J. Clin. Exp. Med. 2014; 7, 3000-4.

[65] RF AbuAlRub. Job stress, job performance, and social support among hospital nurses. J. Nurs. Scholarsh 2004; 36, 73-8.

[66] KK Azida. 2015, Factors Influencing Perceived Stress among Nurses: The Case at National Cancer Institute. Ph.D Dissertation, Universiti Utara Malaysia University, Malaysia.

[67] OAO Akinwolere. Psychological Stress in Critical Care Nurses. Walden University, 2016.

[68] N Ogińska-Bulik. Social support and negative and positive outcomes of experienced traumatic events in a group of male emergency service workers. Int. J. Occup. Saf. Ergon. 2015; 21, 119-27. 
http://wjst.wu.ac.th

[69] N Hamid. The relationship between socio-demographic variables, job stressors and hardiness among nurses in Iran. Afr. J. Nurs. Midwifery 2007; 9, 49-63. 